\title{
PERFIL DE LOS DESEMPLEADOS ECUATORIANOS UN ANÁLISIS MULTIDIMENSIONAL
}

\author{
Ana Paredes ${ }^{1}$ \\ Marisol Sarmiento ${ }^{2}$ \\ Efstathios Stefos ${ }^{3}$
}

\section{RESUMEN}

El objetivo del estudio es investigar el perfil de los desempleados ecuatorianos, para lo cual se realizó un análisis estadístico descriptivo y multidimensional. El estudio utilizó datos de la Encuesta Nacional de Empleo, Desempleo y Subempleo del 2014. El porcentaje de desempleo en hombres y mujeres es muy similar; $49.36 \%$ y $50.64 \%$ respectivamente. El mayor porcentaje de desempleados tienen instrucción media (33.97 \%) y superior universitaria (21.76\%). El 75.90\% de los desempleados viven en el área urbana. $43.90 \%$ de los desempleados son jóvenes. El $81.37 \%$ encuentran sin trabajo por falta de oportunidades. El que no tiene trabajo, en su mayoría, ve mermada el autoestima y el $27.92 \%$ tiene depresión.

Palabras clave: desempleo, análisis estadístico multidimensional

\section{ABSTRACT}

The aim of the study is to investigate the profile of unemployed Ecuadorians, for which a descriptive and multidimensional statistical analysis was realized. The study used data from the National Survey of Employment, Unemployment and Underemployment of 2014. The unemployment rate in men and women is very similar; $49.36 \%$ and

\footnotetext{
${ }^{1}$ Pontificia Universidad Católica del Ecuador, Facultad de Ciencias Exactas y Naturales, Quito, Ecuador (aparedes667@puce.edu.ec).

2 Pontificia Universidad Católica del Ecuador, Facultad de Ciencias Exactas y Naturales, Quito, Ecuador (nsarmiento842@puce.edu.ec).

${ }^{3}$ Pontificia Universidad Católica del Ecuador, Facultad de Ciencias Exactas y Naturales, Proyecto Prometeo, Quito, Ecuador (estefos@aegean.gr).
} 
$50.64 \%$ respectively. The educational level of the majority of the unemployed persons is secondary education (33.97\%) and higher education (21.76\%). 75.90\% of the unemployed live in urban areas and $43.90 \%$ of them are young. $81.37 \%$ of the unemployed persons are out of work due to lack of opportunities. The majority of the unemployed persons have low self-esteem and $27.92 \%$ suffer from depression.

Key words: unemployment, multidimensional statistical analysis

\section{INTRODUCCIÓN}

El presente trabajo contribuye a tener una visión actual de los desempleados ecuatorianos en lo concerniente a sexo, edad, estado civil, nivel de instrucción, raza, tiempo que no han trabajado, razón de desempleo, entre otras variables (Papapostolou \& Stefos, 2013).

Mejorar la calidad de vida es la aspiración de todo ser humano; la manera más segura de lograrlo es contar con un empleo que sea legalmente establecido y remunerado. Trabajar es un derecho y un deber social. Sin embargo, no todos los ciudadanos pueden ejercer este de- recho. Las tasas de desempleo varían cada semestre y generalmente no presentan porcentajes bajos.

El objetivo de este estudio es investigar el perfil de los desempleados ecuatorianos, para lo cual se realiza un análisis estadístico descriptivo y multidimensional con el fin de mostrar las frecuencias y los porcentajes de las variables y los principales criterios de diferenciación y clasificación en grupos de las personas investigadas. Los métodos empleados son el análisis factorial y el análisis jerárquico (Sarmiento Sarmiento et al, 2016).

\section{METODOLOGÍA}

El estudio utilizó datos de la Encuesta Nacional de Empleo, Desempleo y Subempleo de 2014 (INEC, 2014). En el marco del presente estudio, se realizaron un análisis descriptivo y un análisis estadístico multidimensional. El análisis descriptivo muestra las frecuencias y los porcentajes de las variables que estudia la investigación (Athanasiadis, 1995).
El análisis estadístico multidimensional se utiliza con el fin de mostrar las principales y más importantes criterios de diferenciación y la clasificación en grupos de las personas investigadas. Los métodos que utiliza son el análisis factorial de correspondencias múltiples que muestra los criterios de diferenciación y la agrupación jerárquica que define los 
grupos de las personas debido a sus características comunes (Stefos et al, 2011).

El método de análisis factorial de correspondencias múltiples se utiliza con el fin de encontrar cómo las personas se diferencian según sus respuestas. Este método investiga la correlación de las variables de la encuesta de forma simultánea. Los ejes factoriales son los criterios de diferenciación que expresan las oposiciones de las respuestas de las personas.
El análisis jerárquico muestra los grupos de las personas de acuerdo a sus respuestas y características comunes. Este método también presenta un gráfico de clasificación que conecta estos grupos (Papapostolou et al, 2013).

Se utilizó el software SPAD v.4.5 para el análisis de los datos, ofrecido por la Facultad de Humanidades de la Universidad del Egeo. 


\section{ANÁLISIS DESCRIPTIVO}

Tabla 1: Área de residencia de los desempleados ecuatorianos

\begin{tabular}{|lcr|}
\hline & n. $^{\circ}$ & $\%$ \\
\hline Urbana & 1430 & 75.90 \\
Rural & 454 & 24.10 \\
Total & 1884 & 100.00 \\
\hline
\end{tabular}

$75.90 \%$ de los ecuatorianos que están desempleados viven en el área urbana y $24.10 \%$ viven en el área rural (Tabla 1, Gráfico 1).

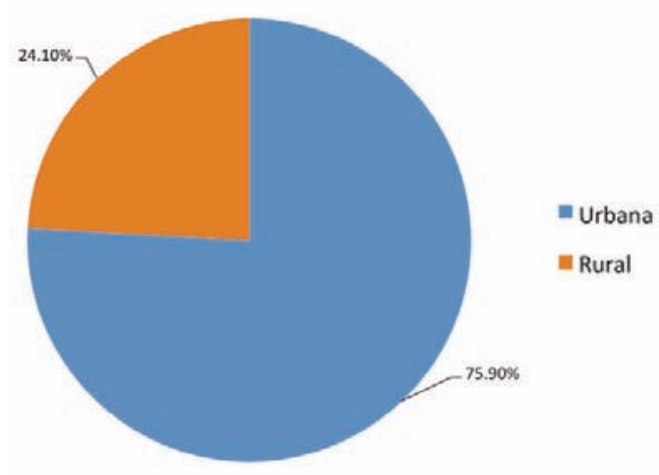

Gráfico 1: Área de residencia de los desempleados ecuatorianos 
Tabla 2: Sexo de los desempleados ecuatorianos

\begin{tabular}{|lcc|}
\hline & n. $^{\circ}$ & $\%$ \\
\hline Hombres & 930 & 49.36 \\
Mujeres & 954 & 50.64 \\
Total & 1884 & 100.00 \\
\hline
\end{tabular}

El $49.36 \%$ de los ecuatorianos que se encuentran desempleados son hombres y el $50.64 \%$ son mujeres (Tabla 2, Gráfico 2).

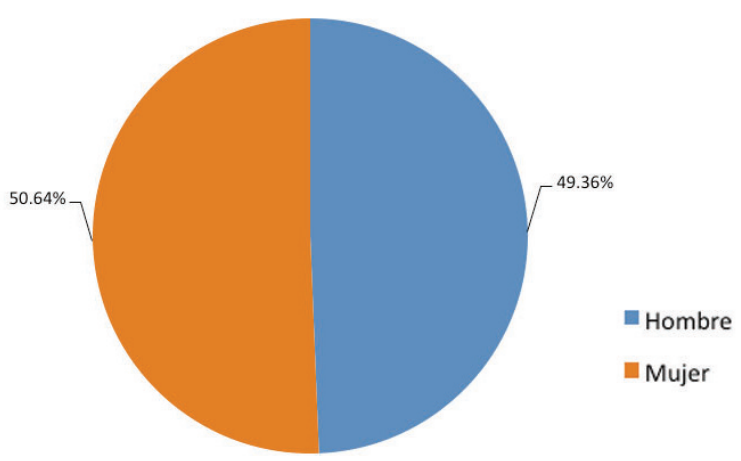

Gráfico 2: Sexo de los desempleados ecuatorianos 


\section{Tabla 3: Edad de los desempleados ecuatorianos}

\begin{tabular}{|lcr|}
\hline Edad & $\mathbf{n .}^{\circ}$ & \multicolumn{1}{c|}{$\%$} \\
\hline$[15,25)$ & 827 & 43.90 \\
{$[25,35)$} & 529 & 28.08 \\
{$[35,45)$} & 249 & 13.22 \\
{$[45,55)$} & 155 & 8.23 \\
{$[55,65)$} & 88 & 4.67 \\
{$[65,75)$} & 29 & 1.54 \\
{$[75,85)$} & 7 & 0.37 \\
Total & 1884 & 100.00 \\
\hline
\end{tabular}

El $43.90 \%$ de los ecuatorianos desempleados son personas jóvenes que se encuentran entre los 15 y 24 años de edad, $28.08 \%$ son personas entre los 25 y 34 años de edad, $13.22 \%$ son personas entre los 35 y 44 años de edad, $8.23 \%$ son personas entre los 45 y 54 años de edad, $4.67 \%$ tienen edades comprendidas entre 55 y 64 años, $1.54 \%$ son personan entre 65 y 74 años de edad y el $0.37 \%$ tienen edades entre 75 y 84 años (Tabla 3, Gráfico 3).

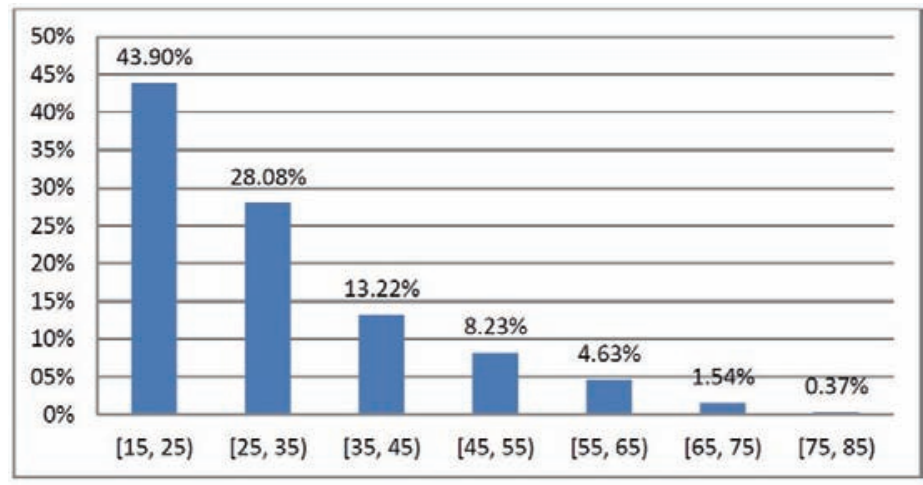

Gráfico 3: Edad de los desempleados ecuatorianos 
Tabla 4: Estado civil de los desempleados ecuatorianos

\begin{tabular}{|lcr|}
\hline & n. & \multicolumn{1}{c|}{$\%$} \\
\hline Casado(a) & 352 & 18.68 \\
Separado(a) & 136 & 7.22 \\
Divorciado(a) & 44 & 2.34 \\
Viudo(a) & 27 & 1.43 \\
Unión libre & 300 & 15.92 \\
Soltero(a) & 1025 & 54.41 \\
Total & 1884 & 100.00 \\
\hline
\end{tabular}

$18.68 \%$ de las personas son casadas, $7.22 \%$ son separadas, $2.34 \%$ son diencuentran en unión libre y 54.41 \% son vorciadas, $1.34 \%$ son viudos, $15.92 \%$ se

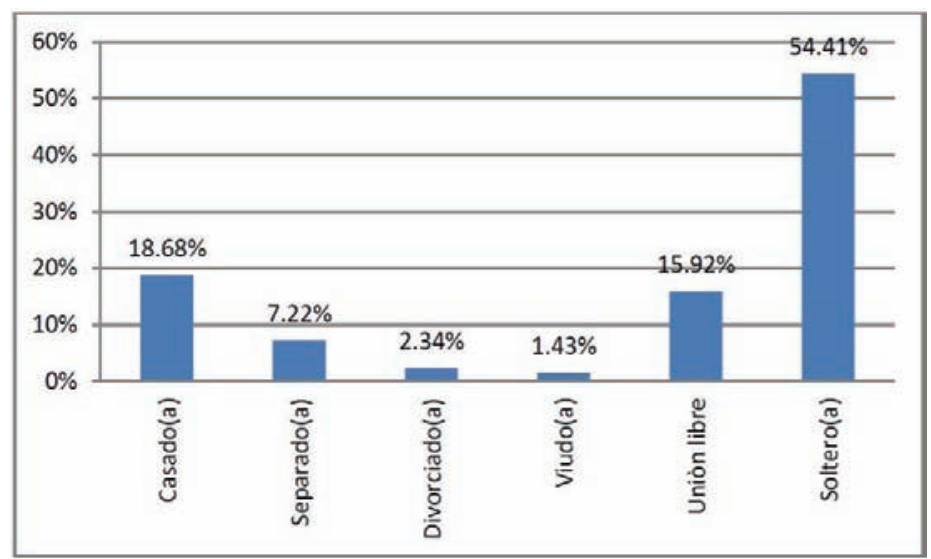

Gráfico 4: Estado civil de los desempleados ecuatorianos 
PERFIL DE LOS DESEMPLEADOS ECUATORIANOS.

UN ANÁLISIS MULTIDIMENSIONAL

Tabla 5: Asiste a clases

\begin{tabular}{|lcr|}
\hline & n. $^{\circ}$ & \multicolumn{1}{c|}{$\%$} \\
\hline Sí & 125 & 6.63 \\
No & 1759 & 93.37 \\
Total & 1884 & 100.00 \\
\hline
\end{tabular}

$6.63 \%$ de los desempleados ecuatorianos asiste a clases y $93.37 \%$ no asiste a clases (Tabla 5, Gráfico 5).

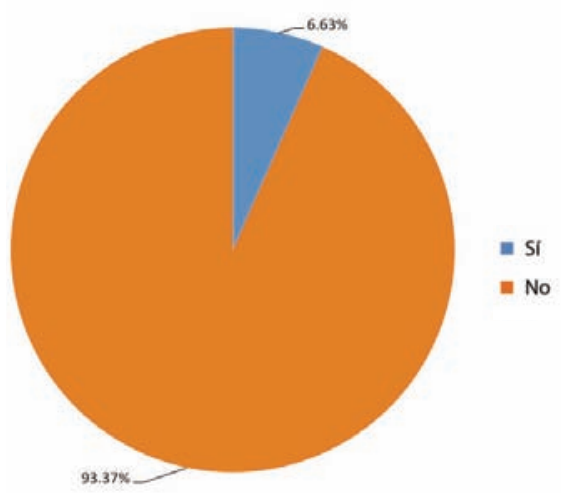

Gráfico 5: Asiste a clases 
Tabla 6: Nivel de instrucción

\begin{tabular}{|lcr|}
\hline & n. $^{\circ}$ & \multicolumn{1}{c|}{$\%$} \\
\hline Ninguno & 18 & 0.96 \\
Centro de alfabetización & 4 & 0.21 \\
Primaria & 299 & 15.87 \\
Educación Básica & 103 & 5.47 \\
Secundaria & 640 & 33.97 \\
Educación Media & 370 & 19.64 \\
Superior no universitario & 29 & 1.54 \\
Superior Universitario & 410 & 21.76 \\
Posgrado & 11 & 0.58 \\
Total & 1884 & 100.00 \\
\hline
\end{tabular}

$0.96 \%$ de las personas ecuatorianas desempleadas no poseen ningún nivel de instrucción, $0.21 \%$ se educaron en centros de alfabetización, $15.87 \%$ de las personas poseen instrucción Prima- ria, $5.47 \%$ Educación Básica, $33.97 \%$ Secundaria, 19.64 \% Educación Media, $1.54 \%$ Superior no universitario, $21.76 \%$ Superior universitario y $0.58 \%$ Posgrado (Tabla 6, Gráfico 6).

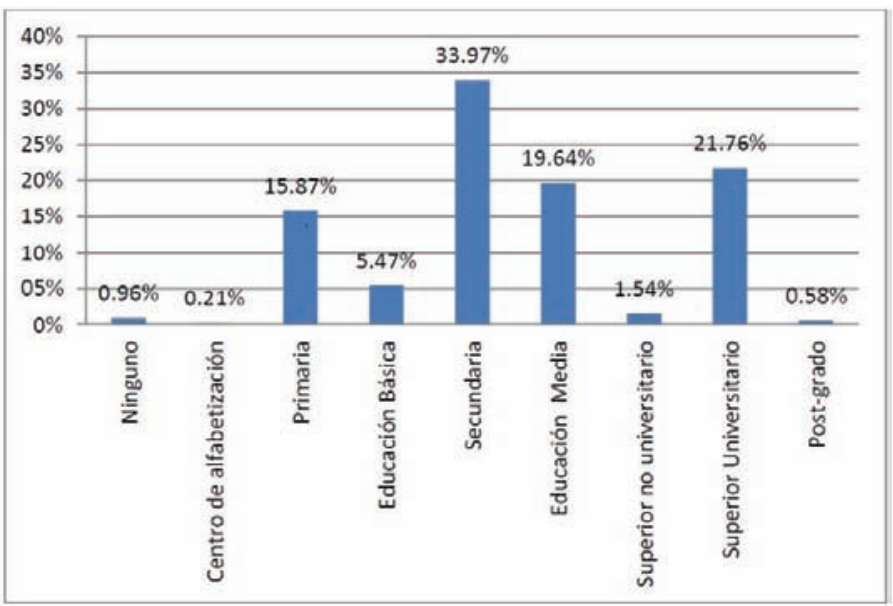

Gráfico 6: Nivel de instrucción 


\section{Tabla 7: Idioma que hablan}

\begin{tabular}{|lcc|}
\hline & $\mathrm{n}^{\circ}$ & $\%$ \\
\hline Solo lengua indígena & 1 & 0.05 \\
Lengua indígena y español & 77 & 4.09 \\
Solo español & 1768 & 93.84 \\
Español e idioma extranjero & 36 & 1.91 \\
Idioma extranjero & 1 & 0.05 \\
No habla & 1 & 0.05 \\
Total & 1884 & 100.0 \\
\hline
\end{tabular}

$0.05 \%$ hablan sólo lengua indí- idioma extranjero, 0.05 \% idioma extrangena, $4.09 \%$ lengua indígena y español, jero (Tabla7, Gráfico 7). 93.84 \% sólo español, $1.91 \%$ español e

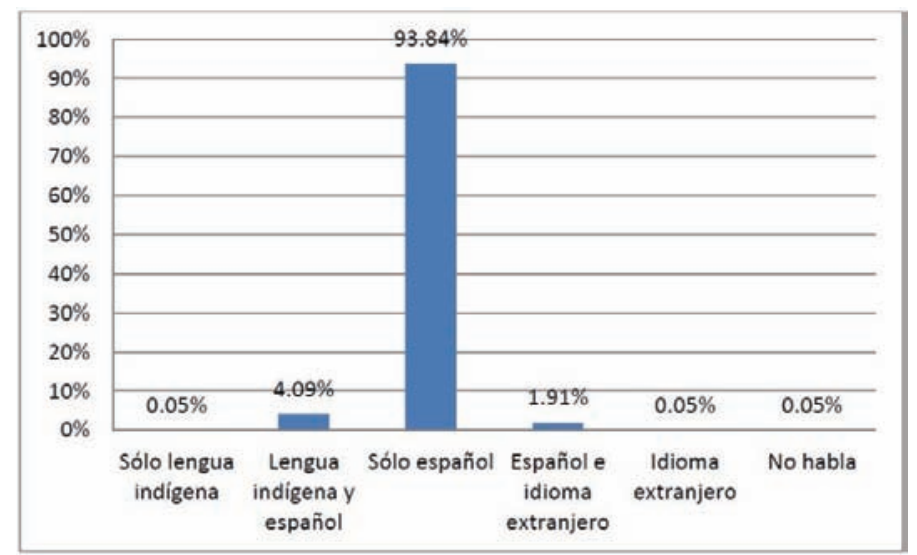

Gráfico 7: Idioma que hablan 
Tabla 8: Cómo se considera

\begin{tabular}{|lcc|}
\hline & $\mathbf{n .}^{\circ}$ & $\%$ \\
\hline Indígena & 104 & 5.52 \\
Afroecuatoriano & 74 & 3.93 \\
Negro & 49 & 2.60 \\
Mulato & 18 & 0.96 \\
Montubio & 48 & 2.55 \\
Mestizo & 1557 & 82.64 \\
Blanco & 34 & 1.80 \\
Total & 1884 & 100.0 \\
\hline
\end{tabular}

$5.52 \%$ se consideran indígena, mestizo, y $1.80 \%$ blanco (Tabla 8, Gráfico $3.93 \%$ afroecuatoriano, $2.60 \%$ negro, 8).

$0.96 \%$ mulato, $2.55 \%$ montubio, $82.64 \%$

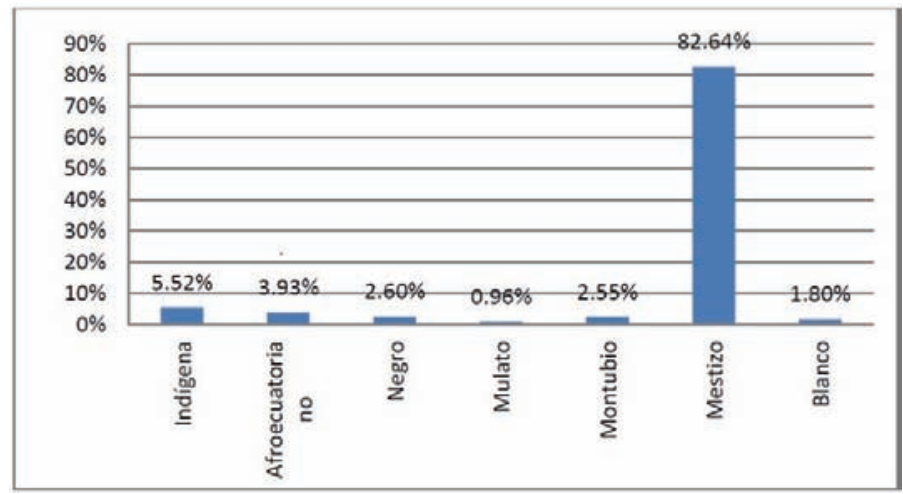

Grafico 8: Cómo se considera 


\section{Tabla 9: Buscó trabajo el mes anterior}

\begin{tabular}{|lrr|}
\hline & n. & \multicolumn{1}{c|}{$\%$} \\
\hline Acudir a sitios de contratación temporal & 118 & 6.26 \\
Hablar con amigos o parientes & 504 & 26.75 \\
Buscar en la prensa o radio & 94 & 4.99 \\
Acudir a agencias de empleo & 88 & 4.67 \\
Tratar de establecer su propio taller, negocio & 29 & 1.54 \\
Asistir a entrevistas & 86 & 4.56 \\
Colocar carteles en tiendas o negocios & 4 & 0.21 \\
Buscar por Internet & 98 & 5.20 \\
Enviar hoja de vida & 374 & 19.85 \\
Otra gestión & 10 & 0.53 \\
No realizó ninguna gestión & 479 & 25.42 \\
Total & 1884 & 100.00 \\
\hline
\end{tabular}

$6.26 \%$ acudió a sitios de contratación temporal, $26.75 \%$ hablo con amigos o parientes $4.99 \%$ buscó en la prensa o radio, $4.67 \%$ acudió a agencias de empleo, $1.54 \%$ trató de establecer su propio taller, negocio, el $4.56 \%$ asistió a entrevistas, $0.21 \%$ colocó carteles en tiendas o negocios, $5.20 \%$ buscó por Internet, $19.85 \%$ envió hoja de vida, $0.53 \%$ realizó otra gestión y el 25.42 \% no realizó ninguna gestión (Tabla 9, Gráfico 9).

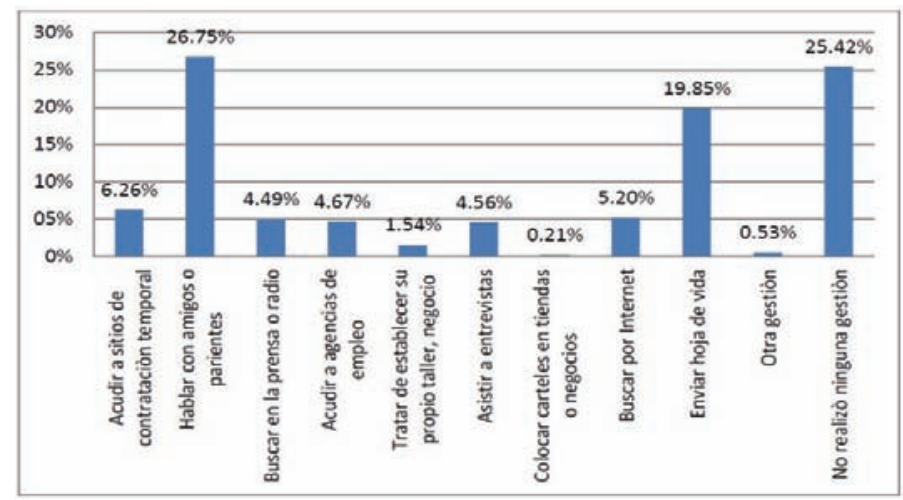

Gráfico 9: Buscó trabajo el mes anterior 


\section{Tabla 10: Meses que busca trabajo}

\begin{tabular}{|lcr|}
\hline & $\mathbf{n}^{\circ}$ & \multicolumn{1}{c|}{$\%$} \\
\hline 1 & 522 & 27.71 \\
2 & 290 & 15.39 \\
3 & 166 & 8.81 \\
4 & 73 & 3.87 \\
5 & 61 & 3.24 \\
6 & 93 & 4.94 \\
7 & 17 & 0.90 \\
8 & 29 & 1.54 \\
9 & 11 & 0.58 \\
10 & 18 & 0.96 \\
11 & 7 & 0.37 \\
12 & 30 & 1.59 \\
13 & 88 & 4.67 \\
NA & 479 & 25.42 \\
Total & 1884 & 100.00 \\
\hline
\end{tabular}

$27.71 \%$ buscó trabajo durante $1 \quad 0.58 \% 9$ meses, $0.96 \% 10$ meses, $0.37 \%$ mes, $15.39 \% 2$ meses, $8.81 \% 3$ meses, 11 meses, $1.59 \% 12$ meses, $4.67 \% 13$ 3.87 \% 4 meses, $3.24 \% 5$ meses, $4.94 \%$ meses (Tabla 10, Gráfico 10). 6 meses, $0.90 \% 7$ meses, $1.54 \% 8$ meses,

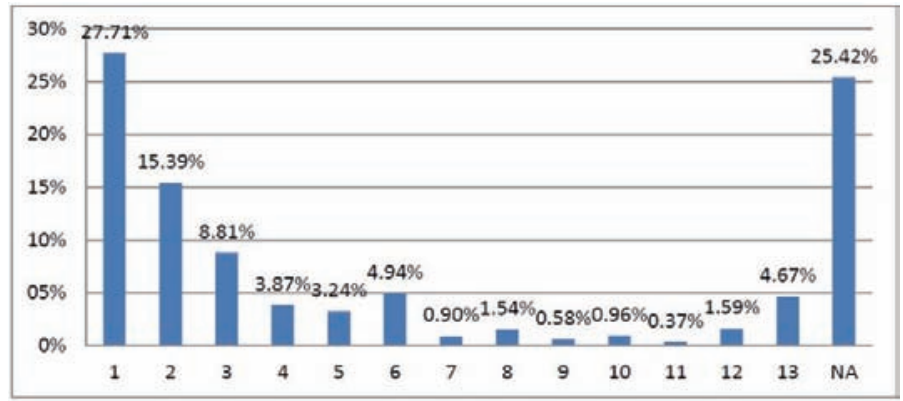

Gráfico 10: Meses que busca trabajo 


\section{Tabla 11: Razón por la que no buscó trabajo}

\begin{tabular}{|lcc|}
\hline & $\mathbf{n .}^{\circ}$ & $\%$ \\
\hline Trabajo ocasional & 25 & 1.33 \\
Tiene trabajo para empezar inmediatamente & 12 & 0.64 \\
Espera respuesta a una gestión & 30 & 1.59 \\
Espera respuesta de un empleador & 52 & 2.76 \\
Espera cosecha o temporada de trabajo & 19 & 1.01 \\
Piensa que no le darán trabajo & 93 & 4.94 \\
No cree poder encontrar & 248 & 13.16 \\
NA & 1405 & 74.58 \\
Total & 1884 & 100.00 \\
\hline
\end{tabular}

$1.33 \%$ de los desempleados ecua- dor, $1.01 \%$ espera cosecha o temporada torianos no buscaron trabajo porque de trabajo, $4.94 \%$ piensa que no le tiene trabajo ocasional, $0.64 \%$ tiene tra- darán trabajo, $13.16 \%$ no cree poder enbajo para empezar inmediatamente, contrar, $74.58 \%$ no responde (Tabla 11, $1.59 \%$ espera respuesta a una gestión, Gráfico 11).

$2.76 \%$ espera respuesta de un emplea-

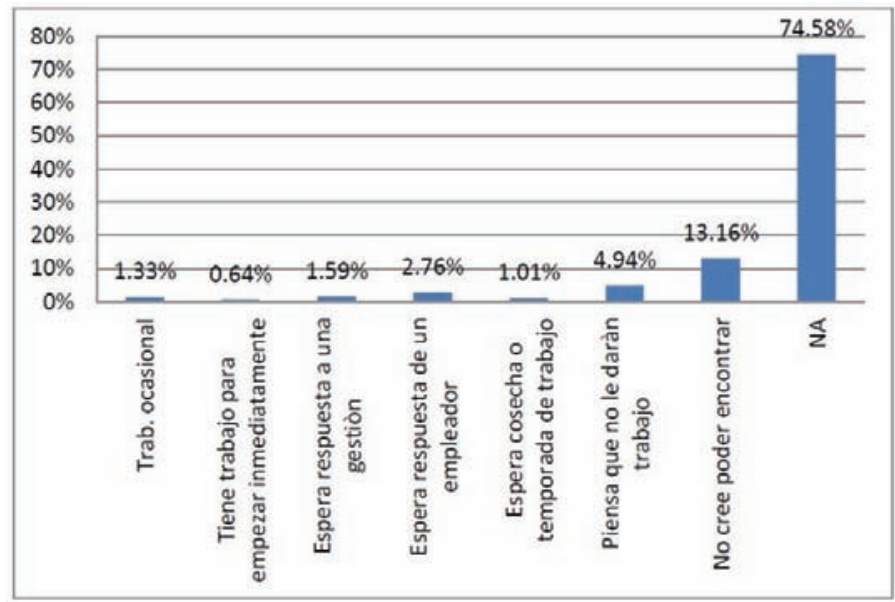

Gráfico 11: Razón por la que no buscó trabajo 
Tabla 12: Trabajó anteriormente

\begin{tabular}{|lcr|}
\hline & n. & \multicolumn{1}{c|}{$\%$} \\
\hline Sí & 1250 & 66.35 \\
No & 634 & 33.65 \\
Total & 1884 & 100.00 \\
\hline
\end{tabular}

El 66.35 \% sí trabajó anteriormente, y el 33.65 \% no (Tabla 12, Gráfico 12).

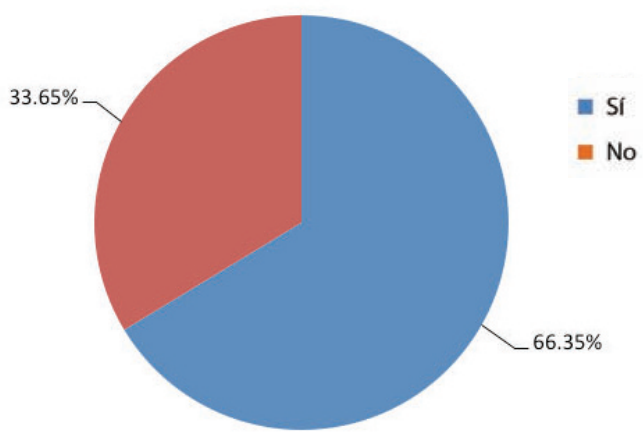

Gráfico 12: Trabajó anteriormente 
Tabla 13: Motivos por los que dejó de trabajar

\begin{tabular}{|lcc|}
\hline & $\mathbf{n .}^{\circ}$ & $\%$ \\
\hline Liquidación empresa & 73 & 3.87 \\
Despido intempestivo & 167 & 8.86 \\
Renuncia voluntaria & 276 & 14.65 \\
Supresión partidas & 14 & 0.74 \\
Terminación contrato & 398 & 21.13 \\
Fue mal en el negocio & 75 & 3.98 \\
Terminó ciclo agrícola & 99 & 5.25 \\
Se jubiló o pensionaron & 4 & 0.21 \\
Otro & 144 & 7.64 \\
NA & 634 & 33.65 \\
Total & 1884 & 100.0 \\
\hline
\end{tabular}

$3.87 \%$ de los ecuatorianos desem- das; $21.13 \%$ terminaron su contrato; pleados dejaron de trabajar por liquida- $3.98 \%$ les fue mal en el negocio; $5.25 \%$ ción empresarial; 8.86 \% por despido porque terminó el ciclo agrícola y $0.21 \%$ intempestivo; 14.65 \% por renuncia vo- por jubilación (Tabla 13, Gráfico 13). luntaria; $0.74 \%$ por supresión de parti-

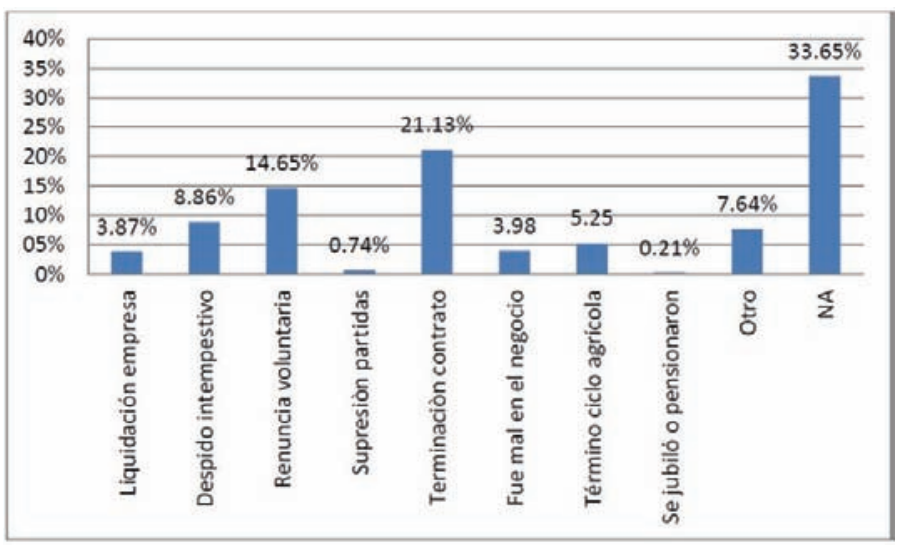

Gráfico 13: Motivos por los que dejó de trabajar 


\section{Tabla 14: Número de meses que no trabaja}

\begin{tabular}{|lcr|}
\hline & $\mathrm{n}^{\circ}$ & $\%$ \\
\hline 1 & 275 & 14.60 \\
2 & 211 & 11.20 \\
3 & 149 & 7.91 \\
4 & 75 & 3.98 \\
5 & 74 & 3.93 \\
6 & 92 & 4.88 \\
7 & 18 & 0.96 \\
8 & 51 & 2.71 \\
9 & 26 & 1.38 \\
10 & 31 & 1.65 \\
11 & 4 & 0.21 \\
12 & 50 & 2.65 \\
13 & 194 & 10.30 \\
14 & 634 & 33.65 \\
Total & 1884 & 100.00 \\
\hline
\end{tabular}

$14.60 \%$ de los desempleados $0.96 \%$ no trabajan 7 meses; $2.71 \%$ no ecuatorianos no trabajan durante 1 mes; trabajan 8 meses; $1.38 \%$ no trabajan $11.20 \%$ no trabajan durante 2 meses; 9 meses; $1.65 \%$ no trabajan 10 meses; $7.91 \%$ no trabajan durante 3 meses; $0.21 \%$ no trabajan 11 meses; $2.65 \%$ no $3.98 \%$ no trabajan durante 4 meses; trabajan 12 meses; $10.30 \%$ no trabajan $3.93 \%$ no trabajan durante 5 meses; 13 meses y $33.65 \%$ no trabajan durante 4.88 \% no trabajan durante 6 meses; 14 meses (Tabla 14, Gráfico 14).

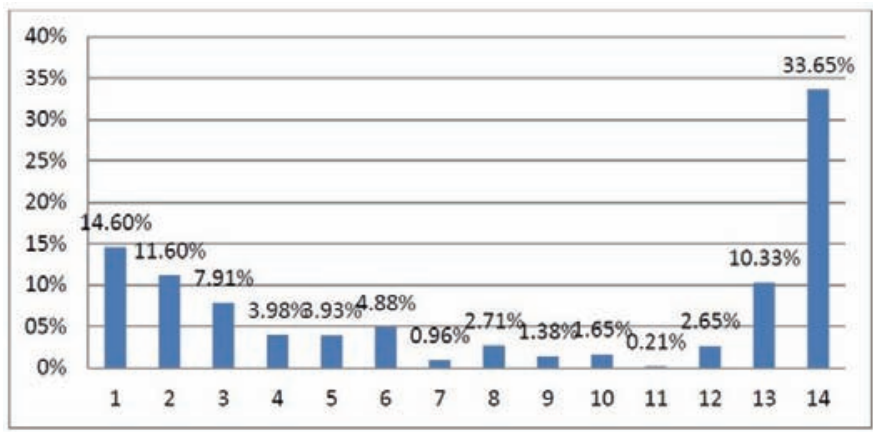

Gráfico 14: Número de meses que no trabaja 
Tabla 15: Se encuentra sin trabajo por

\begin{tabular}{|lcr|}
\hline & $\mathbf{n}^{\circ}$ & $\%$ \\
\hline Falta de oportunidades en la actualidad & 1533 & 81.37 \\
Resultado de sus errores del pasado & 108 & 5.73 \\
Motivos personales / familiares & 237 & 12.58 \\
Fenómenos / desastres naturales & 6 & 0.32 \\
Total & 1884 & 100.0 \\
\hline
\end{tabular}

$81.37 \%$ de los ecuatorianos se en- $\quad 12.58 \%$ por motivos personales y $0.32 \%$ cuentra sin trabajo por falta de oportu- $\quad$ se encuentran sin trabajo por fenómenidades; 5.73 \% no tienen trabajo como nos / desastres naturales (Tabla 15, Gráresultado de sus errores del pasado; fico 15).

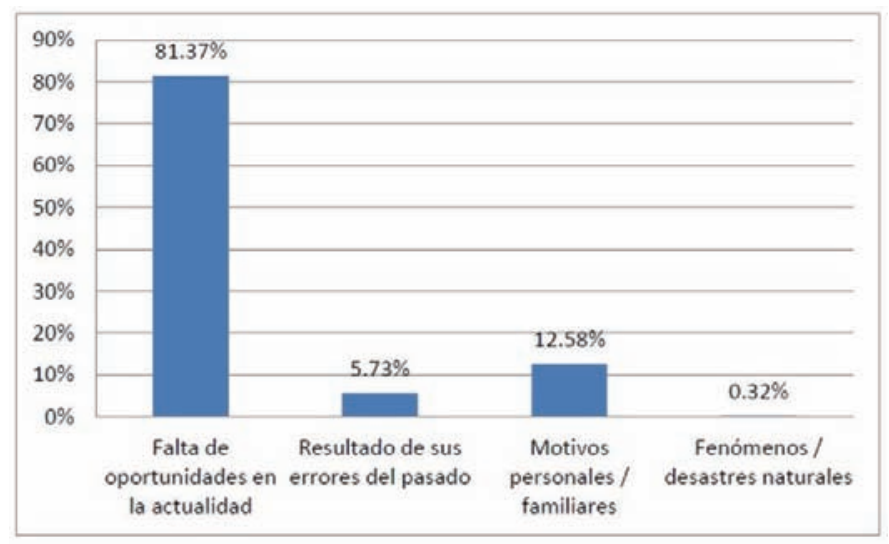

Gráfico 15: Se encuentra sin trabajo por 
Tabla 16: Tiene deterioro de sus habilidades

\begin{tabular}{|lcc|}
\hline & n. & $\%$ \\
\hline Sí & 626 & 33.23 \\
No & 1258 & 66.77 \\
Total & 1884 & 100.0 \\
\hline
\end{tabular}

$33.23 \%$ de los ecuatorianos que se lidades y $66.77 \%$ respondieron que no encuentran desempleados respondie- tienen deterioro de sus habilidades ron que sí tienen deterioro de sus habi- (Tabla 16, Gráfico 16).

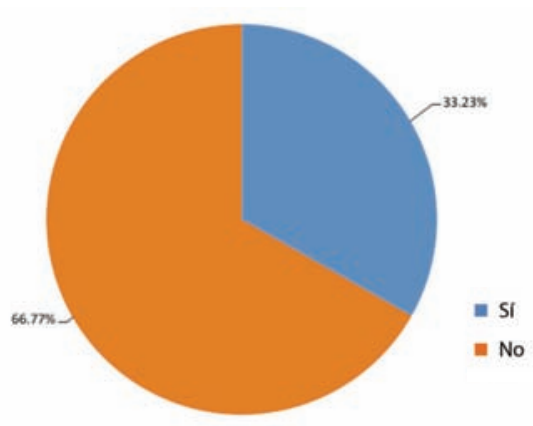

Gráfico 16: Tiene deterioro de sus habilidades 
PERFIL DE LOS DESEMPLEADOS ECUATORIANOS.

UN ANÁLISIS MULTIDIMENSIONAL

\section{Tabla 17: Tiene disminución de su autoestima}

\begin{tabular}{|lcr|}
\hline & n. $^{\circ}$ & \multicolumn{1}{c|}{$\%$} \\
\hline Sí & 964 & 51.17 \\
No & 920 & 48.83 \\
Total & 1884 & 100.00 \\
\hline
\end{tabular}

$51.17 \%$ de los ecuatorianos des- nución de su autoestima (Tabla 17, Gráempleados si tienen disminución de su fico 17).

autoestima y $48.83 \%$ no tienen dismi-

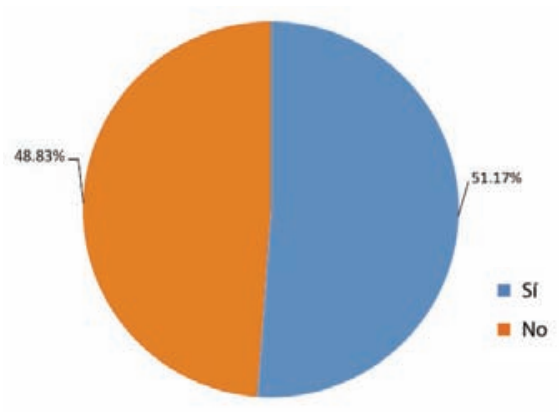

Gráfico 17: Tiene disminución de su autoestima 
Revista PUCE, ISSN 1012-389X. Núm, 102

3 Nov 2015-3 mayo 2016. Paredes, SARmiento, Stefos, pr. 325-368

Tabla 18: Tiene depresión

\begin{tabular}{|lcr|}
\hline & n. & \multicolumn{1}{c|}{$\%$} \\
\hline Sí & 526 & 27.92 \\
No & 1358 & 72.08 \\
Total & 1884 & 100.00 \\
\hline
\end{tabular}

$27.92 \%$ de los desempleados no tienen depresión (Tabla 18, Gráfico ecuatorianos tienen depresión y $72.08 \%$ 18).

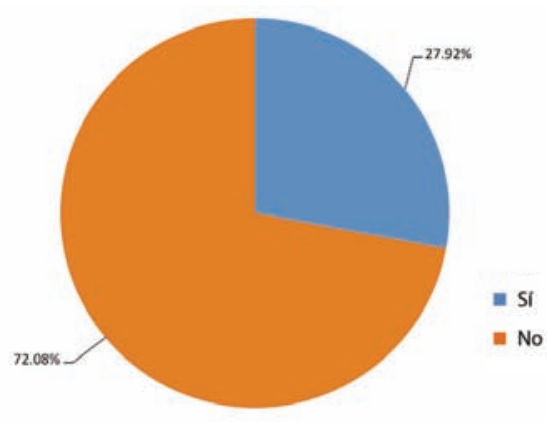

Gráfico 18: Tiene depresión 
Tabla 19: Tiene falta de superación personal y profesional

\begin{tabular}{|lcc|}
\hline & n. $^{\circ}$ & $\%$ \\
Sí & 776 & 41.19 \\
No & 1108 & 58.81 \\
Total & 1884 & 100.0 \\
\hline
\end{tabular}

$41.19 \%$ de los ecuatorianos de- falta de superación personal y profesiosempleados tienen falta de superación nal (Tabla 19, Gráfico 19). personal y profesional, $58.81 \%$ no tienen

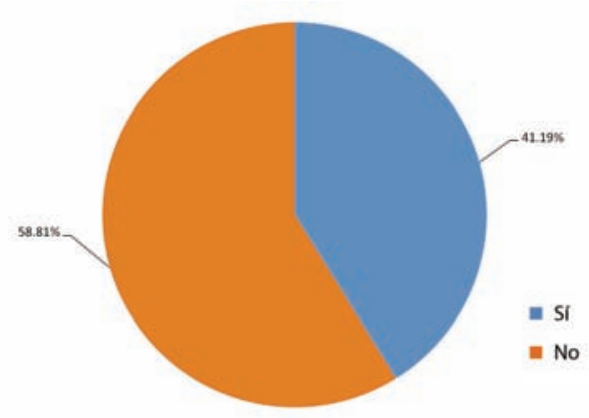

Gráfico 19: Tiene falta de superación personal y profesional 
Tabla 20: Por ser desempleado ha tenido que gastar ahorros

\begin{tabular}{|lcr|}
\hline & n. $^{\circ}$ & \multicolumn{1}{c|}{$\%$} \\
\hline Sí & 1035 & 54.94 \\
No & 849 & 45.06 \\
Total & 1884 & 100.00 \\
\hline
\end{tabular}

El $54.94 \%$ de ecuatorianos por ser ahorros, y el $45.06 \%$ no ha tenido que desempleado ha tenido que gastar sus gastar ahorros (Tabla 20, Gráfico 20).

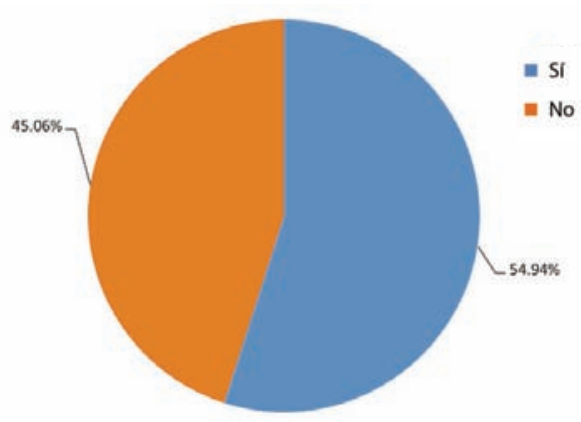

Gráfico 20: Por ser desempleado ha tenido que gastar ahorros 
Tabla 21: Por ser desempleado ha tenido que vender bienes

\begin{tabular}{|lcr|}
\hline & n. & $\%$ \\
Sí & 222 & 11.78 \\
No & 1662 & 88.22 \\
Total & 1884 & 100.0 \\
\hline
\end{tabular}

El 11.78\% de ecuatorianos por ser bienes, y el $88.22 \%$ no (Tabla 21, Grádesempleados han tenido que vender fico 21).

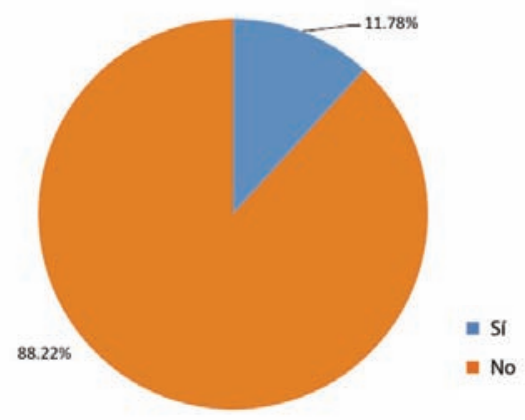

Gráfico 21: Por ser desempleado ha tenido que vender bienes 
Tabla 22: Por ser desempleado ha tenido que endeudarse

\begin{tabular}{|lcr|}
\hline & n. $^{\circ}$ & \multicolumn{1}{c|}{$\%$} \\
\hline Sí & 673 & 35.72 \\
No & 1211 & 64.28 \\
Total & 1884 & 100.00 \\
\hline
\end{tabular}

El 35.72\% por ser desempleado ha ha tenido que endeudarse (Tabla 22, tenido que endeudarse, y el $64.28 \%$ no Gráfico 22).

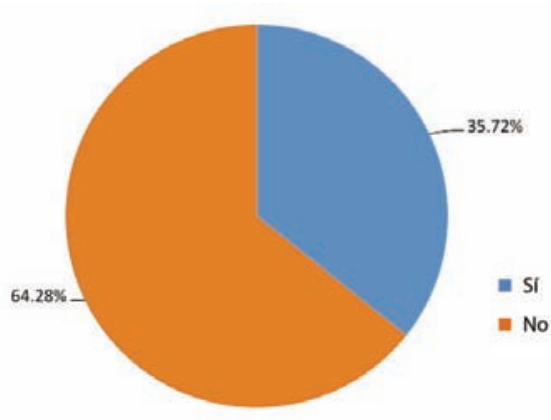

Gráfico 22: Por ser desempleado ha tenido que endeudarse 
Tabla 23: Por ser desempleado ha tenido que comprar productos baratos

\begin{tabular}{|lcc|}
\hline & n. $^{\circ}$ & $\%$ \\
\hline Sí & 1109 & 58.86 \\
No & 775 & 41.14 \\
Total & 1884 & 100.0 \\
\hline
\end{tabular}

El $58.86 \%$ de ecuatorianos por ser nido que comprar productos baratos desempleado ha tenido que comprar (Tabla 23, Gráfico 23). productos baratos, el $41.14 \%$ no ha te-

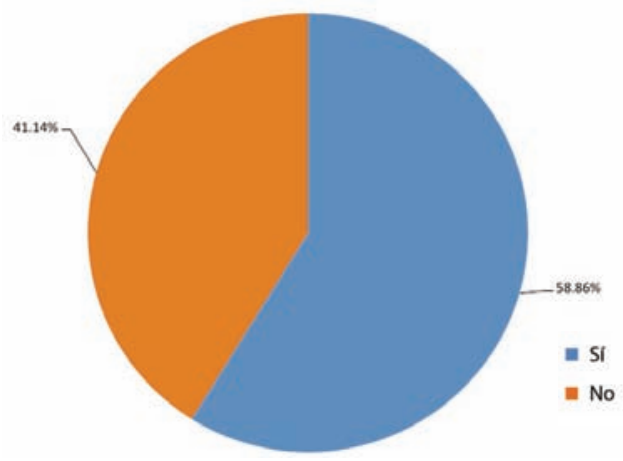

Gráfico 23: Por ser desempleado ha tenido que comprar productos baratos 
Tabla 24: Por ser desempleado ha disminuido el consumo de alimentos

\begin{tabular}{|lcc|}
\hline & n. $^{\circ}$ & $\%$ \\
\hline Sí & 929 & 49.31 \\
No & 955 & 50.69 \\
Total & 1884 & 100.0 \\
\hline
\end{tabular}

El $49.31 \%$ de ecuatorianos por ser disminuido el consumo de alimentos desempleado ha disminuido el con- (Tabla 24, Gráfico 24). sumo de alimentos, y el $50.69 \%$ no han

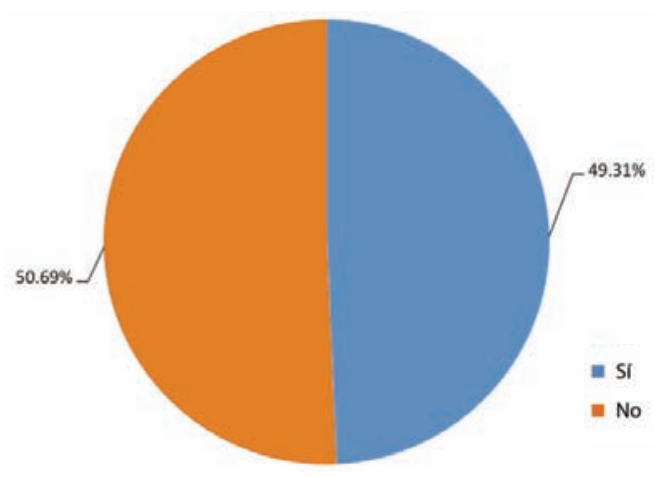

Gráfico 24: Por ser desempleado ha disminuido el consumo de alimentos 
Tabla 25: Por ser desempleado ha disminuido la compra de vestido

\begin{tabular}{|lcr|}
\hline & n. $^{\circ}$ & \multicolumn{1}{c|}{$\%$} \\
\hline Sí & 1122 & 59.55 \\
No & 762 & 40.45 \\
Total & 1884 & 100.00 \\
\hline
\end{tabular}

El $59.55 \%$ por ser desempleado $40.45 \%$ no ha disminuido la compra de ha disminuido la compra de vestido, y el vestido (Tabla 25, Gráfico 25).

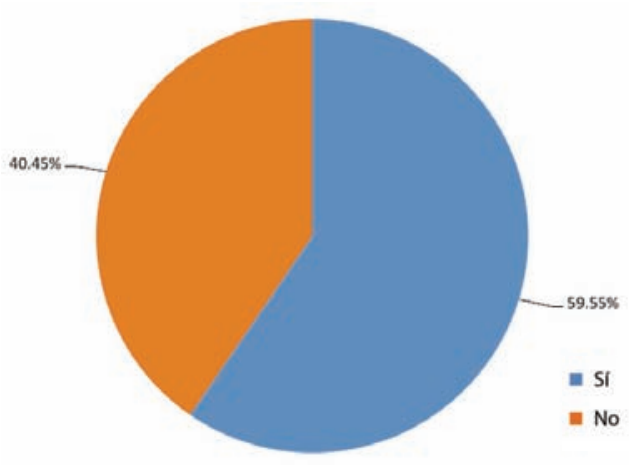

Gráfico 25: Por ser desempleado ha disminuido la compra de vestido 
Tabla 26: Por ser desempleado cambió a estudiantes de establecimientos

\begin{tabular}{|lcr|}
\hline & n. $^{\circ}$ & $\%$ \\
\hline Sí & 162 & 8.60 \\
No & 1722 & 91.40 \\
Total & 1884 & 100.00 \\
\hline
\end{tabular}

$8.60 \%$ de los desempleados ecua- ron de establecimiento (Tabla 26, Grátorianos cambiaron a estudiantes de es- fico 26). tablecimientos y $91.40 \%$ no les cambia-

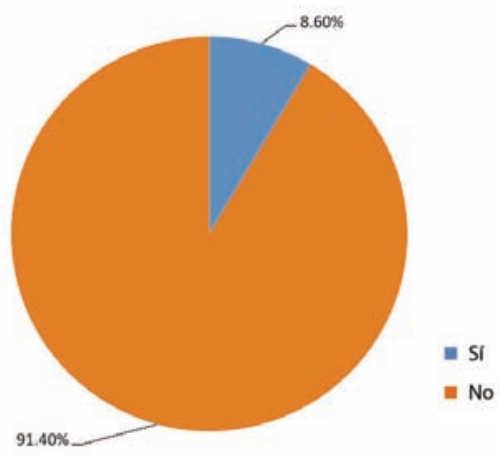

Gráfico 26: Por ser desempleado cambió a estudiantes de establecimientos 
PERFIL DE LOS DESEMPLEADOS ECUATORIANOS.

UN ANÁLISIS MULTIDIMENSIONAL

Tabla 27: Está embarazada o en periodo de lactancia

\begin{tabular}{|lcr|}
\hline & n. $^{\circ}$ & \multicolumn{1}{c|}{$\%$} \\
\hline Sí & 60 & 3.18 \\
No & 834 & 44.27 \\
NA & 990 & 52.55 \\
Total & 1884 & 100.00 \\
\hline
\end{tabular}

$3.18 \%$ de las mujeres ecuatorianas pondieron a esta pregunta (Tabla 27, desempleadas están embarazadas; $44.27 \%$ Gráfico 27).

no están embarazadas y $52.55 \%$ no res-

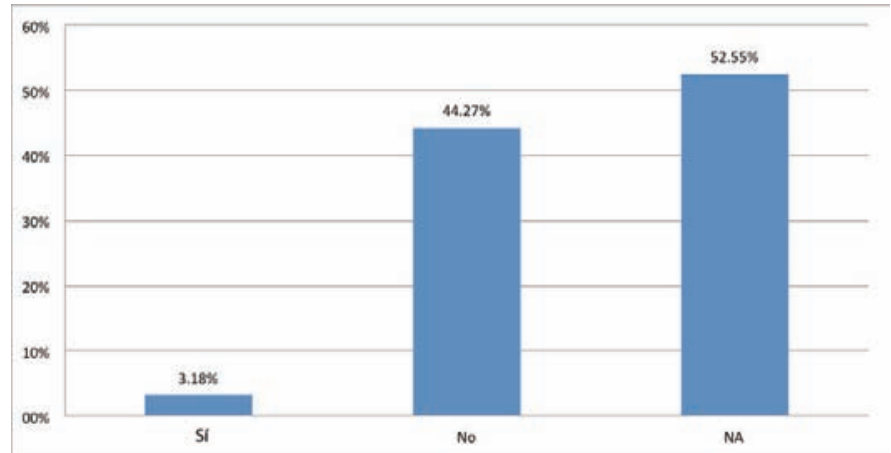

Gráfico 27: Está embarazada o en periodo de lactancia 


\section{Tabla 28: Tiene teléfono celular activado}

\begin{tabular}{|lcc|}
\hline & n. & $\%$ \\
Sí & 1346 & 71.44 \\
No & 520 & 27.60 \\
NA & 18 & 0.96 \\
Total & 1884 & 100.0 \\
\hline
\end{tabular}

$71.44 \%$ de los ecuatorianos de- celular activado y $0.96 \%$ no respondiesempleados tienen teléfono celular ac- ron esta pregunta (Tabla 28, Gráfico 28). tivado; $27.60 \%$ no tienen teléfono

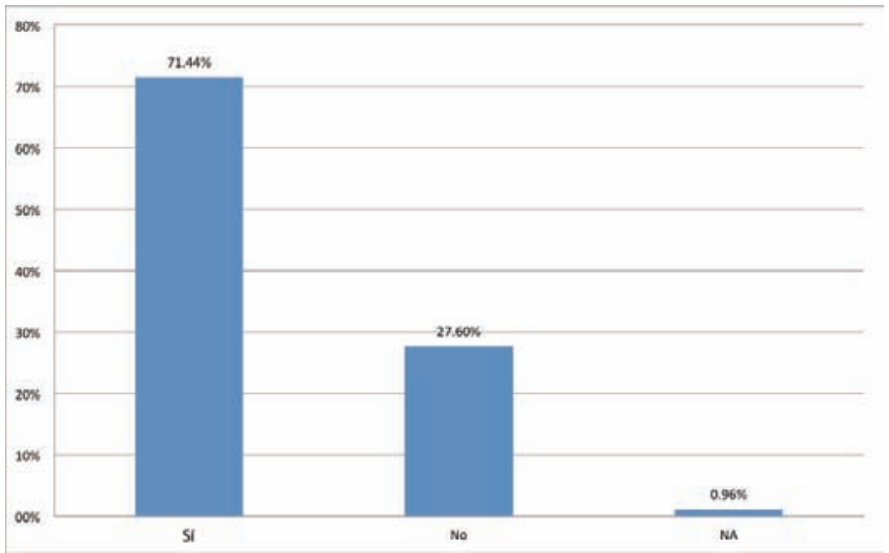

Gráfico 28: Tiene teléfono celular activado 
Tabla 29: En los últimos 12 meses ha usado computador

\begin{tabular}{|lcr|}
\hline & n. & \multicolumn{1}{c|}{$\%$} \\
\hline Sí & 1225 & 65.02 \\
No & 641 & 34.02 \\
NA & 18 & 0.96 \\
Total & 1884 & 100.00 \\
\hline
\end{tabular}

$65.02 \%$ de los desempleados usado computadory $0.96 \%$ no responecuatorianos han usado computador en dieron esta pregunta (Tabla 29, Gráfico los últimos 12 meses; $34.02 \%$ no han 29).

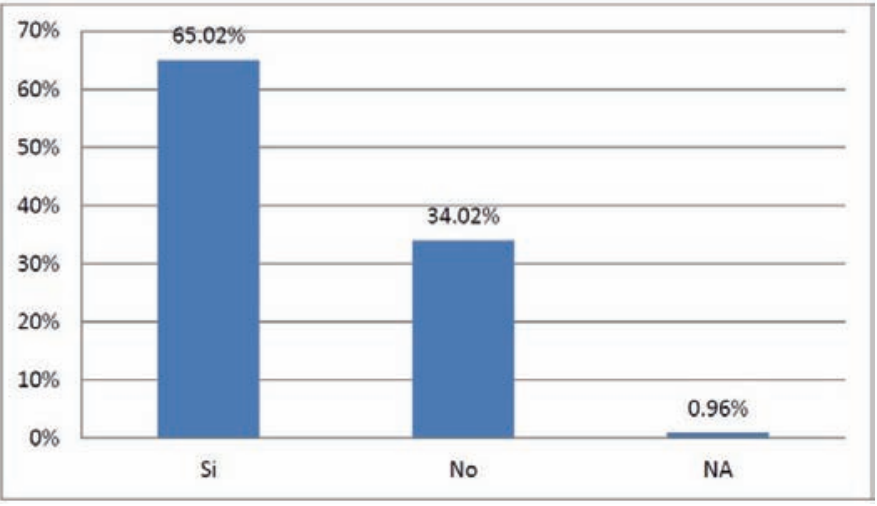

Gráfico 29: En los últimos 12 meses ha usado computador 
Tabla 30: En últimos 12 meses ha usado internet

\begin{tabular}{|lcr|}
\hline & n. $^{\circ}$ & \multicolumn{1}{c|}{$\%$} \\
Sí & 1215 & 64.49 \\
No & 651 & 34.55 \\
NA & 18 & 0.96 \\
Total & 1884 & 100.00 \\
\hline
\end{tabular}

El $64.49 \%$ de ecuatorianos en últi- $\quad 34.55 \%$ no ha usado internet (Tabla 30, mos 12 meses ha usado internet, el Gráfico 30).

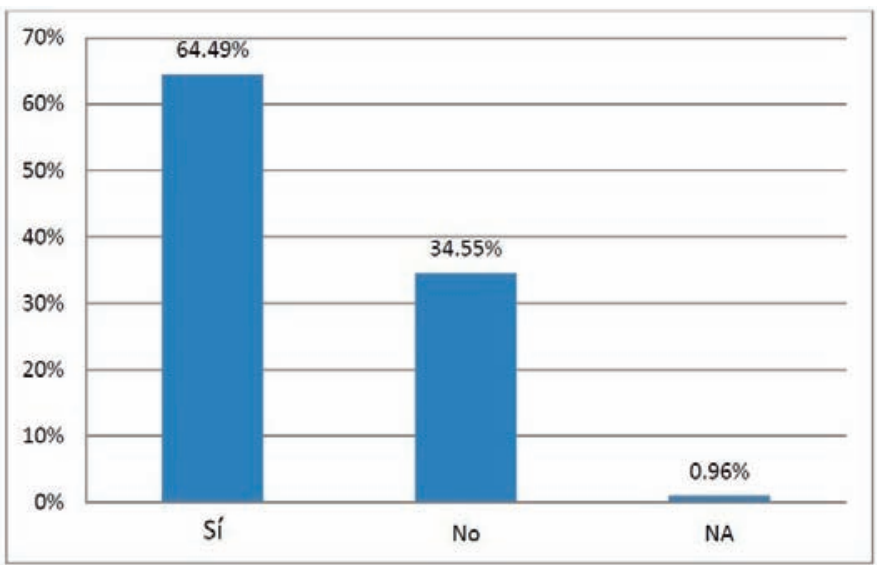

Gráfico 30: En últimos 12 meses ha usado internet 
Tabla 31: En los últimos 12 meses ha asistido a algún curso de capacitación

\begin{tabular}{|lcr|}
\hline & n. & \multicolumn{1}{c|}{$\%$} \\
\hline Sí & 136 & 7.22 \\
No & 1729 & 91.77 \\
NA & 19 & 1.01 \\
Total & 1884 & 100.00 \\
\hline
\end{tabular}

$7.22 \%$ en los últimos 12 meses sí curso de capacitación (Tabla 31, Gráfico ha asistido a algún curso de capacita- 31). ción, y el $91.77 \%$ no ha asistido a algún

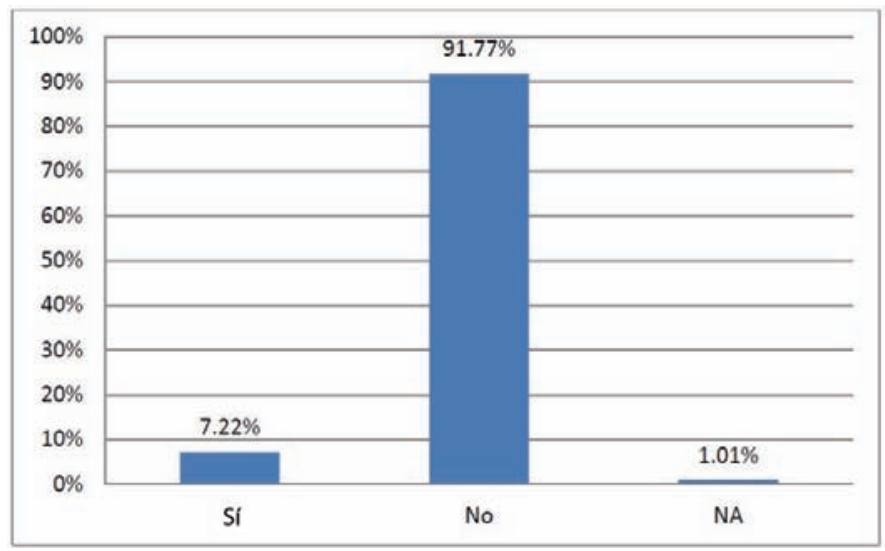

Gráfico 31: En los últimos 12 meses ha asistido a algún curso de capacitación 
Tabla 32: Región natural

\begin{tabular}{|lcc|}
\hline & n. $^{\circ}$ & $\%$ \\
\hline Sierra & 808 & 42.89 \\
Costa & 692 & 36.73 \\
Amazonía & 374 & 19.85 \\
Insular & 10 & 0.53 \\
Total & 1884 & 100.0 \\
\hline
\end{tabular}

El $42.89 \%$ de desempleados ecua- amazonía y $0.53 \%$ a la región insular torianos pertenecen a la región natural (Tabla 32, Gráfico 32).

Sierra, $36.73 \%$ a la Costa, $19.85 \%$ a la

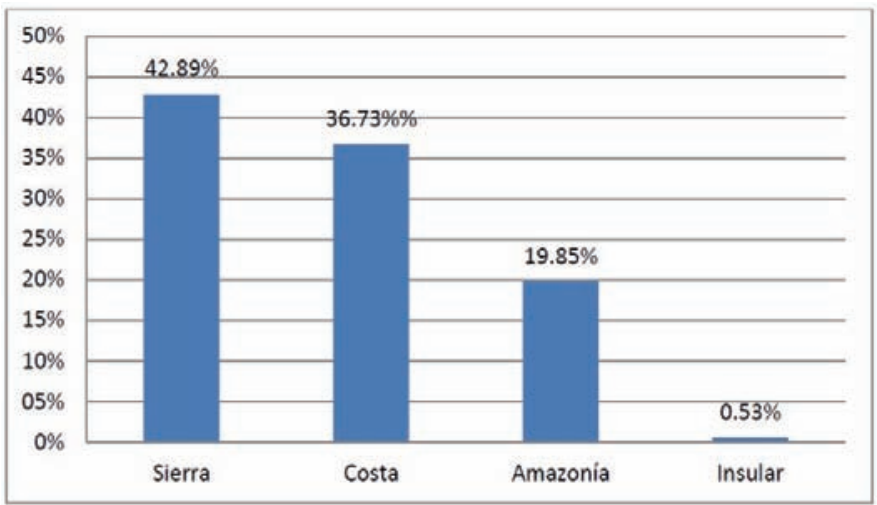

Gráfico 32: Región natural 
PERFIL DE LOS DESEMPLEADOS ECUATORIANOS.

UN ANÁLISIS MULTIDIMENSIONAL

Tabla 33: Condición de actividad nueva

\begin{tabular}{|lcc|}
\hline & n. $^{\circ}$ & $\%$ \\
\hline Desempleo abierto & 1405 & 74.58 \\
Desempleo oculto & 479 & 25.42 \\
Total & 1884 & 100.0 \\
\hline
\end{tabular}

$74.58 \%$ de los desempleados dieron que son desempleados ocultos ecuatorianos respondieron que son de- (Tabla 33, Gráfico 33). sempleados abiertos y $25.42 \%$ respon-

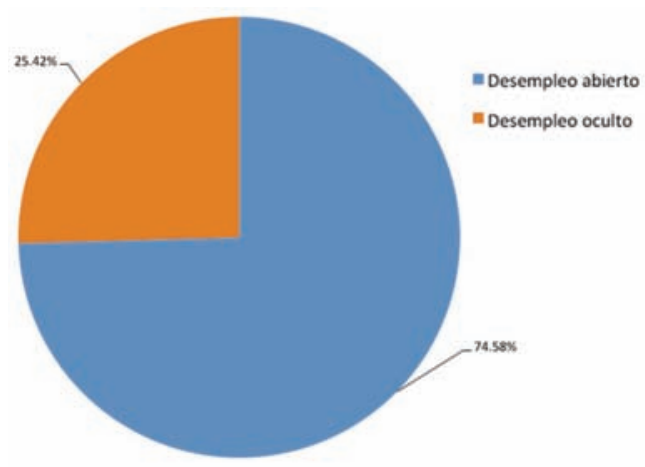

Gráfico 33: Condición de actividad nueva 


\section{ANÁLISIS FACTORIAL DE CORRESPONDENCIAS MÚLTIPLES}

El método de análisis factorial de correspondencias múltiples se utilizó para encontrar cómo las personas que participaron en la encuesta son diferenciadas según sus respuestas (Stefos \& Koulianidi, 2016). Los criterios que diferencian a las personas son los siguientes:

Primer criterio de diferenciación (porcentaje de inercia 6.35\%)

En el primer eje, por un lado, hay personas que trabajaron anteriormente, son desempleados abiertos y buscaron trabajo el mes anterior hablando con amigos. Por otro, hay personas que no buscaron trabajo el mes anterior, su condición de actividad nueva es desempleo oculto, su edad está comprendida entre 15 y 25 años y su estado civil es soltero(a).
Segundo criterio de diferenciación (porcentaje de inercia $5.44 \%$ )

En el segundo eje, por un lado, hay personas que son desempleados abiertos y respondieron que la razón por la cual no buscaron trabajo es porque trabajan ocasionalmente. Por otro, hay personas que pertenecen al área urbana de la región natural de la Amazonía y buscan trabajo los últimos 4 meses.

\section{Tercer criterio de diferenciación} (porcentaje inercia $3.72 \%$ )

En el tercer eje, por un lado, hay hombres que no trabajaron durante el último mes, en los últimos 12 meses no han usado internet ni computadora y tienen un nivel de instrucción primaria. Por otro, hay mujeres que durante los últimos 12 meses han usado internet y computadora y su nivel de instrucción es superior.

\section{ANÁLISIS JERÁRQUICO}

El análisis jerárquico llevó a cinco grupos de 1884 personas que se muestran en la figura 1 (Benzécri, 1992).

\section{Primer grupo (639 personas, $33.91 \%$ de la muestra)}

Los ecuatorianos del primer grupo trabajaron anteriormente y respondieron que son desempleados abiertos. En los 12 últimos meses han usado internet y computadora. Su trabajo terminó por contrato y su nivel de instrucción es superior.

\section{Segundo grupo (339 personas, $17.99 \%$ de la muestra)}

Los ecuatorianos del segundo grupo en los últimos 12 meses no han usado internet ni computadora. Este grupo tiene un nivel de instrucción pri- 
maria. Buscaron trabajo el mes anterior hablando con amigos y su condición de actividad nueva es desempleo abierto.

Tercer grupo (88 personas, $4.67 \%$ de la muestra)

Los ecuatorianos de este grupo se consideran indígenas y el idioma que hablan es la lengua indígena. Pertenecen al área rural de la región natural de la amazonía y no tienen teléfono celular activo.

Cuarto grupo (364 personas, $19.32 \%$ de la muestra)

Los ecuatorianos del cuarto grupo respondieron que no trabajaron ante- riormente por 14 meses. Su condición de actividad nueva es desempleado abierto, su edad está comprendida entre 15 y 25 años y su estado civil es soltero(a).

Quinto grupo (454 personas, $24.09 \%$ de la muestra)

El quinto grupo está formado por ecuatorianos que no buscaron trabajo el mes anterior. Su condición de actividad nueva es desempleo oculto y respondieron que la razón por la cual no buscaron trabajo es porque no creen poder encontrarlo o piensan que no les darán. Este grupo no trabajó anteriormente.

Quinto grupo

454 personas

$24.09 \%$ de la muestra

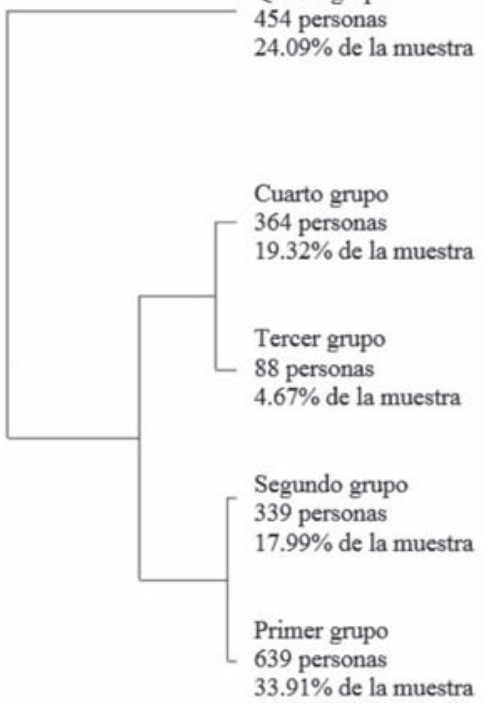

Figura 1: El gráfico de clasificación 
Estas diferencias de los grupos se mostraron en la Figura 2 donde el gráfico del Análisis de Correspondencias (nivel factorial 1×2) presenta los centroides de los cinco grupos en los dos ejes.
También, define las diferencias y las similitudes entre las personas de los cinco grupos (Stefos \& Papapostolou, 2013).

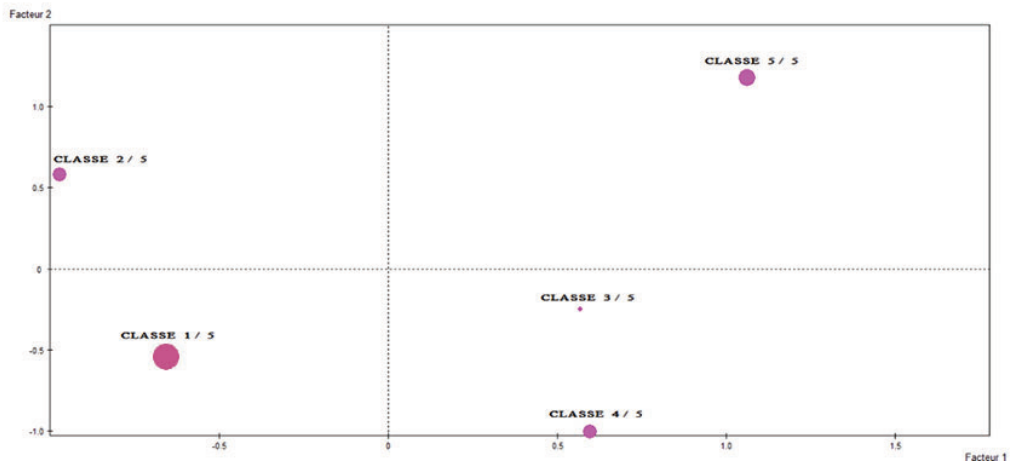

Figura 2: Análisis de correspondencias

\section{CONCLUSIONES}

En este estudio se investigó el perfil de los desempleados ecuatorianos tomando como referencia una muestra de 1884 personas de la encuesta realizada por el INEC; para lo cual se desarrolló un análisis estadístico descriptivo y multidimensional con el fin de mostrar las frecuencias y los porcentajes de las variables y los principales criterios de diferenciación y la clasificación en grupos de las personas investigadas. Los métodos empleados fueron el análisis factorial de correspondencias múltiples y el análisis jerárquico (Koulianidi \& Stefos, 2015).
Los resultados que sobresalen en el estudio descriptivo y son confirmados por el análisis factorial hacen referencia al sexo, nivel de instrucción, raza, área de residencia, edad, motivos por los que se encuentra sin trabajo, uso de tecnología y condición de actividad nueva (Stefos \& Efstathiou, 2013; Olivier, 2008).

El porcentaje de desempleo en hombres y mujeres es muy similar: $49.36 \%$ y $50.64 \%$ respectivamente. El mayor porcentaje de desempleados tienen instrucción media (33.97\%) y superior universitaria (21.76\%). La raza con mayor desem- 
pleo es la mestiza (82.64 \%), el $75.90 \%$ de los desempleados viven en el área urbana; $43.90 \%$ de los desempleados son jóvenes. El 81.37 \% encuentran sin trabajo por falta de oportunidades. El 71.44 $\%$ tiene teléfono celular activado, el 65.02 $\%$ usa computadora e internet y $74.58 \%$ respondieron que su condición de actividad nueva es desempleado abierto.

El 93.37\% no asisten a clases, apenas el 33.9 7\% llega a la secundaria. La mayoría habla español. El $26.75 \%$ habló con amigos y parientes en busca de un trabajo, el $27.71 \%$ ha buscado un mes trabajo, y el $66.35 \%$ sí ha trabajado anteriormente.

El no tener trabajo, a la mayoría, le disminuye el autoestima, el $27.92 \%$ tiene depresión (Stefos, 2015). Una gran parte de desempleados ha tenido que comprar productos baratos, ha disminuido la compra de vestido; pero no ha disminuido el consumo de alimentos, ni se han cambiado de establecimiento de estudio. 


\section{BIBLIOGRAFÍA}

Athanasiadis, I. (1995). Correspondence Analysis and Hierarchical Classification (pp. 5156). Athens: New Technologies Editions.

Benzécri, P. (1992). Correspondence Analysis Handbook. New York: Dekker.

Instituto Nacional de Estadística y Censos - INEC (2014). Encuesta Nacional de Empleo, Desempleo y Subempleo - ENEMDU, 2014. Quito, Ecuador.

Koulianidi, G. \& Stefos, E. (2015). Consequences of Dietary Habits and Endocrine Disruptors in School Performance of Children Aged 10-12 in Greece. American Journal of Food Science and Nutrition. Vol. 2, No. 6, 2015, pp. 113-120.

Papapostolou, I., Papapostoulou, K. \& Stefos, E. (2013). Educational Research. From Qualitative to Quantitative analysis. p.178. Rhodes: Evdimos Editions.

Papapostolou, I. \& Stefos, E. (2013). Qualitative analysis on pedagogical research. Methodological approaches. In I. Papapostolou (Ed.), Educational activities. Teaching Interventions in Secondary Education. pp.244-251. Rhodes: Evdimos Editions.

Sarmiento Sarmiento, N.M., Paredes Proaño, A.M. \& Stefos, E. (2016). Deaths by Suicide in Ecuador: A Quantitative Data Analysis. Review of European Studies; Vol. 8, No. 1; 2016. pp. 145-156.
Stefos, E. \& Koulianidi, G. (2016). Nutrition Data Analysis Using R: Applications in Higher Education. Health Sciences Research. Vol. 3, No. 1, 2016, pp. 10-16.

Stefos, E. (2015). Causes of Death of Indigenous Ecuadorians. International Journal of Clinical Medicine Research. Vol. 2, No. 6, 2015, pp. 65-70.

Stefos, E. \& Efstathiou, I. (2013). Quantitative analysis of the data of the School of Trianta during the period of 1906-1916. In I. Papapostolou (Ed.), Educational activities. Teaching Interventions in Secondary Education. pp.29-57. Rhodes: Evdimos Editions.

Stefos, E. \& Papapostolou, I. (2013). Research Methodology. Processes and suggestions. p.406. Rhodes: Evdimos Editions.

Stefos, E., Athanasiadis I., Gialamas, B. \& Tsolakidis, C. (2011). The Use of New Technologies and the Project Method in Teaching Statistics: A Case Study in Higher Education. HMS i JME, Volume 3. 2010-2011. pp.84-100.

Olivier, M. (2008). The analysis of quantitative data, Transl. Athanasiadis, I. (pp.86-88). Athens:Topos. 